\title{
Assessment of sound insulation of naturally ventilated double skin
}

\author{
facades \\ D. Urbán ${ }^{a,{ }^{*}}$, N.B. Roozen ${ }^{b}$, P. Zatko ${ }^{a}$, M. Rychtáriková ${ }^{c, d}$, P. Tomašovičc ${ }^{c}$ C. Glorieux ${ }^{b}$ \\ ${ }^{a}$ A\&Z Acoustics s.r.o., Repašského 2, 84102, Bratislava, Slovakia \\ ${ }^{b}$ KU Leuven, Dep. of Physics and Astronomy, Soft matter and biophysics, Laboratory of Acoustics, Celestijnenlaan $200 D, 3001$ Leuven, \\ Belgium
}

${ }^{c}$ STU Bratislava, Faculty of Civil Engineering, Dep. of Building Structures, Radlinského 11, 81368 Bratislava, Slovakia

${ }^{d}$ KU Leuven, Faculty of Architecture, Hoogstraat 51, 9000 Gent, Belgium

\begin{abstract}
The sound insulation spectrum is analysed of 18 double glazing arrangements facades, of which 9 double skin facades were measured in situ and 9 in a laboratory setting. The influence of the cavity thickness, the parallelism of the two glass panels, the absorptivity of the cavity and the effect of the size of ventilation slots are investigated. The results are compared with double layer wall insulation prediction models. Also a new, simple model is proposed that predicts the sound insulation of naturally ventilated double skin facades, based on the coincidence frequency, the structural resonance frequencies, the cavity resonance frequencies, the façade construction, the dimensions the and material properties. The model predictions are validated by measurement data.
\end{abstract}

\section{Introduction}

Double skin facades (DSF's) are used in more than half of countries in Europe (27), with the incentive to save energy in the winter period. Most frequently they are implemented as a part of envelope structures in large administrative buildings. The state of the art design of DSFs is the result of many years of research and development in the fields of structural and material design, thermotechnology, daylight and acoustics. DSFs typically appear as elements of intelligent building concepts. Research has been performed to achieve the most effective combination of heating and ventilation 
through openings by making use of integrated logic artificial neural networks [1]. Substantial efforts were spent on performing CFD simulations, measurements and analysis in the field of air flow in the DSF cavity, on the investigation of the influence of the cavity thickness, on the type of ventilation openings, and on façade shading systems $[2,3]$. The growing emergence of the usage of DSF's has opened a discussion on their influence on fire protection of buildings, propagation of fire by the façade construction and also on their behavior in situations of firefighting $[4,5]$. The adequacy of the location and size of vents to prevent overheating of the interior in summer time, while allowing for preheating of the room in colder seasons was studied in [6]. The use of plants in the DSF interspace was also considered as a viable option for limiting heating by sunlight exposure of rooms [7, 8].

From a building acoustics point of view, DSF's offer a way to limit indoor noise even in the case of high exterior noise levels. By virtue of their double leaf structure, even if they allow natural ventilation in administrative buildings, they are effective in keeping indoor sound pressure levels caused by exterior noise to reasonable levels [9-13].

A large number of double wall sound insulation studies have been performed [14-18]. One of first prediction models was proposed by Beranek and Work [19]. Their model assumes perpendicular incidence of acoustic waves, which allows to describe the propagation of through a wall by means of a structural impedance approach. An extension of the model to a diffuse sound field, involving oblique angles of incidence, was introduced by London [20]. Later on, White and Powel [21] introduced a model for bounded panels, taking into account the resonance effects caused by their dimensions. A statistical mechanical approach into wall structure characteristics has been implemented by Lyon and Maidanik [22]. Their work was based on analysis of power flow response between two or more coupled multi-resonant systems to random excitation, determining the coupling between a reverberant acoustic field and a structure by means of a radiation resistance approach. For calculating the acoustic insulation performance of cavities, Mulhoulland and Cummings [23, 24] took into account acoustic wave reflections between the two walls by means of ray-tracing approaches. In 1970, Crocker and Price [25, 26] proposed a Statistical Energy Analysis (SEA) method for building structures, taking into account non-resonant vibrations of walls and dynamic stiffness of structural parts. Another impedance model was designed by Mulholland for double walls without absorptive material inside the 
wall [27]. An alternative impedance matrix method has been developed by Hamad and Tachibana [28]. Au and Byrne [29, 30] introduced an impedance transfer function for flexible nonporous materials, which was later on adapted by Ver [31]. The influence on the sound transmission of the mass per unit area, the bending stiffness and damping, damping has been evaluated by Heckl [32]. One of the first models that took into account acoustic bridges due to connections between layers connection was developed by Sharp [33], who found inspiration in the work of London, Cremer and Heckl [34]. Further work on sound insulation in the presence of rigid construction joints was done by Fahy [35]. Plasterboard double walls were evaluated using a statistical prediction approach by Lin, Garrelick [36], Craik, Wilson [37] and by Green and Sherry [38-40].

Concerning the acoustic properties of naturally ventilated DSFs, researchers studied the influence of adding a second transparent layer on facades on their sound insulation [41]. Others studied the effect of adding absorptive material in the cavity of a DSF [42-45]. The most extensive study was done by Blasco, whose aim was to develop a supplement to standards EN 12354-1 and 3 for DSF's $[46,47]$. He proposed three ways to predict the sound insulation, based on a double wall sound propagation model [48]. DSF sound insulation properties turn out to be influenced by diffraction due to vents on the external facade layer, and also due the finite element of structural elements in general. At low frequencies, diffraction effects can cause a decrease of the accuracy of sound pressure measurements carried out on the external side of building in low frequency range [49]. Diffraction also plays a role with respect to the directivity of sound waves radiated by a slot [50-53]. Barclay et al stressed the importance of an integrated approach to both noise exposure and ventilation performance in urban buildings [54]. Bibby et al looked into the use in practice of ventilation grill acoustic silencers [55]. The influence on the acoustic performance of DFTs of the spacing of the vents and of absorptive materials applied in the cavity was studied in $[56,57]$. Also extensive comparative studies of the acoustic performance of different DSF types have been carried out [58-60].

This article reports on a sound insulation measurement campaign on laboratory and in situ double (transparent) skin structures. Chapter 2 deals with in situ measurements of 9 DSFs and with the influence on their construction solution on the sound insulation. Chapter 3 summarized laboratory measurements of double leaf specimens, their sound insulation, and the analysis of the sound field in 
the cavity. In Chapter 4 the laboratory results are compared with different prediction models. Based on the observations, in Chapter 5, the above mentioned existing sound insulation prediction models are integrated into one simple model.

\section{In situ measurements of DSF sound insulation}

In situ measurements were carried out in the city of Bratislava on eight DSFs, and one double skin facade element (DSFE) on a dwelling house at Trnava road (DHTR). The measurements were carried out in accordance with standard EN ISO 16283-1 [61], with the addition of one microphone M2 inside of the cavity. Microphone M1 was placed outside the cavity, at 2m in front of the façade. Microphone M3 was placed in the receiving room inside the building (Fig. 1a). Microphones M1 and M2 were positioned at $1.5 \mathrm{~m}$ above ground level. The positions of microphone M3 were in accordance to the recommendations of standard EN ISO 16283-1 (at least six random positions per measurement). The outdoor traffic noise was used as the source of sound, except for some cases, where amplified pink noise was used instead. The measurements were done by class 1 measuring analyzer devices according to the IEC 61672-1 [62]. The room acoustic parameters were determined according to EN ISO 3382-2 [63]. According to the Slovak legislation (Announcement of the Ministry of Health of the Slovak Republic 549/2007 and Slovak Republic Government prescription 115/2006), the objective assessment of indoor acoustic comfort should be done by long term measurements. The here presented sound insulation measurements were done over a short time period (usually during $15 \mathrm{~min}$ of traffic). Therefore, strictly speaking, the results do not allow to judge if indoor requirements were fulfilled. Nevertheless it is noteworthy that in each of the measured cases A- weighted equivalent sound pressure level $\left(L_{\text {Aeq }}\right)$ during the measurement period was lower than the limits in the legislation. In all cases, the $L_{\text {Aeq }}$ value was less than $40 \mathrm{~dB}(\mathrm{~A})$ and the reverberation time was shorter than $0.6 \mathrm{~s}$.

The measured facades were quite different from each other from a structural as well as from a geometrical point of view (Tab. 1) [64]. 
Table 1 General data of DSF and DSFE geometry.

\begin{tabular}{|c|c|c|c|c|c|c|c|c|c|}
\hline & \multicolumn{2}{|c|}{ Slotted DSF } & \multicolumn{4}{|c|}{ Corridor DSF ventilated by grills } & \multicolumn{3}{|c|}{ Corridor DSF ventilated by slots } \\
\hline Name of building & DBC & DHTR & NBS & SLSP & UCB & IS & SCST & SN & DP \\
\hline $\mathrm{V}_{\text {R.R. }}\left(\mathrm{m}^{3}\right)$ & 59.1 & 31.3 & 59.3 & 127 & 185.4 & 51 & 51.9 & 54.5 & 82 \\
\hline $\mathrm{d}(\mathrm{m})$ & 0.17 & 0.280 & 0.6 & 0.65 & 0.85 & 0.67 & 0.85 & 1.350 & 0.880 \\
\hline Length $_{\text {DSF }}(\mathrm{m})$ & 1.5 & 2.6 & 3.75 & $>10$ & $1.5 \mathrm{x}^{4)}$ & $1.22 \mathrm{x}^{4)}$ & $1.6 \mathrm{x}$ & $>10$ & $>10$ \\
\hline Height $_{\text {DSF }}(\mathrm{m})$ & 3.6 & 2.74 & 3.45 & 3.575 & 3.3 & 3.3 & 3 & 3 & $3 \mathrm{x}^{1)}$ \\
\hline Ext. glazing $(\mathrm{mm})$ & $8^{6)}$ & $5.5^{7)}$ & $12^{6)}$ & $12^{6)}$ & $10^{6)}$ & $2 \times 8^{5)}$ & $10^{6)}$ & $7^{6)}$ & $12^{6)}$ \\
\hline Int. glazing $(\mathrm{mm})$ & $4-16-8$ & $3-52-3$ & $4-16-4$ & $2 \times 6-8-8$ & $4-10-4$ & $6-16-6$ & $4-10-4$ & $4-10-4$ & $8-12-8$ \\
\hline Vent. Opening (\%) & 3.5 & 1.4 & 7.06 & 13.59 & 6.67 & 14.85 & 2) & 2) & 2) \\
\hline $\begin{array}{l}\text { Size of ventilation } \\
\text { slot }(\mathrm{mm})\end{array}$ & $\begin{array}{l}16 \times 200 x \\
75 \times 8\end{array}$ & $\begin{array}{l}1820 \times 20 \\
\times 2\end{array}$ & $\begin{array}{l}240 \mathrm{x} \\
1250^{3)}\end{array}$ & $\begin{array}{l}520 \mathrm{x} \\
2800^{3)}\end{array}$ & $\begin{array}{l}220 \mathrm{x} \\
1500^{3)}\end{array}$ & $\begin{array}{l}490 \times 1 \\
200^{3)}\end{array}$ & 2) & 2x) & 2) \\
\hline$L_{\text {Aeq (ext) }}(\mathrm{dB})$ & 63.5 & 69.6 & 61.5 & 66.4 & 69.6 & 60.2 & 72.5 & 72.9 & 72.1 \\
\hline$L_{\text {Aeq (int) }}(\mathrm{dB})$ & 33.6 & 31.9 & 31.3 & 30.6 & 36.9 & 28.6 & 38.4 & 38 & 36.9 \\
\hline$T_{20, f=1000 \mathrm{~Hz}}(\mathrm{~dB})$ & 0.6 & 0.6 & 1.3 & 0.5 & 0.6 & 0.5 & 0.6 & 0.8 & 0.7 \\
\hline$D_{2 m}(\mathrm{~dB})$ & 5 & 9.5 & 5 & 7 & 7.5 & 4.5 & 6 & 7 & 4.5 \\
\hline$D_{2 m, n T w}\left(C ; C_{t r}\right)(\mathrm{dB})$ & $40(-2 ; 5)$ & $40(-2 ; 5)$ & $\begin{array}{l}40(-1 ;- \\
4)\end{array}$ & $34(-2 ; 0)$ & $\begin{array}{l}39(-1 ;- \\
3)\end{array}$ & $\begin{array}{l}35(-1 ;- \\
3)\end{array}$ & $36(-2 ;-5)$ & $\begin{array}{l}37(-1 ;- \\
3)\end{array}$ & $35(-1 ;-5)$ \\
\hline
\end{tabular}

Building of Faculty of Civil Engineering on Technical University of Slovakia in Bratislava (DBC);

Dwelling house at Trnava road, Bratislava (DHTR); Building of National Bank of Slovakia (NBS)

[65]; Slovak Savings Bank headquarter (SLSP); UniCredit Bank headquarters, Bratislava (UCB);

Ingsteel company headquarters, Bratislava (IS); Building of Slovak Centre of Scientific and Technical

Information, Bratislava (SCST); Slovanet company headquarters, Bratislava (SN); Digital Partk 1,

Bratislava (DP);

1) Cavity divided by a perforated metal based sheet (Fig. 1);

2) Naturally ventilation through slots between adjacent glass panels;

3) Vents across the full width of the facade;

4) DSF cavity length continuous over the facade;

5) Laminated glass;

6) Tempered glass;

7) Standard floated glass without any specification; 


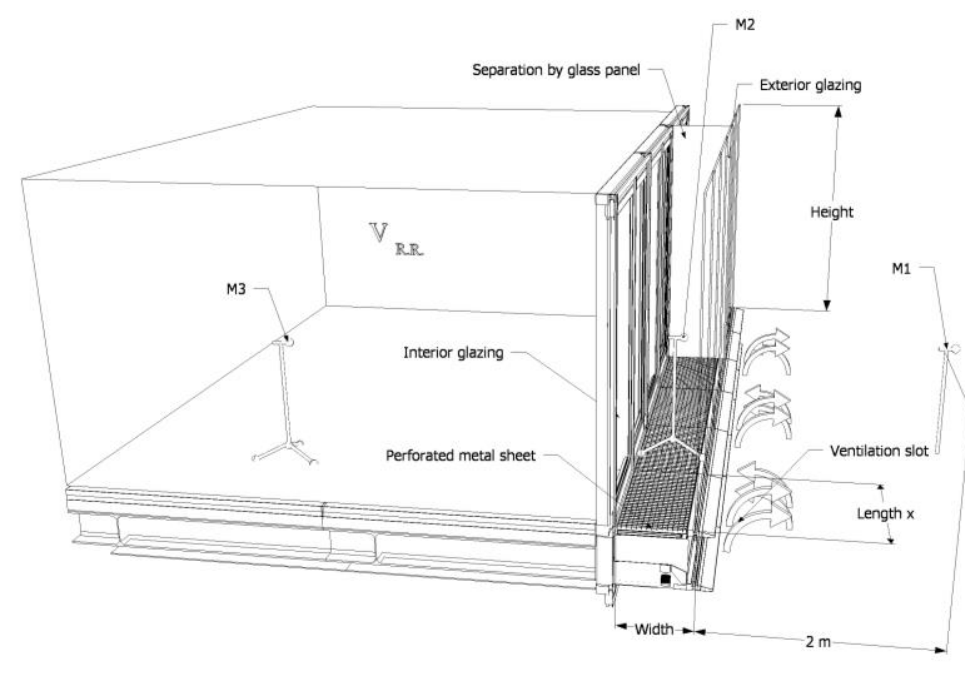

(a)

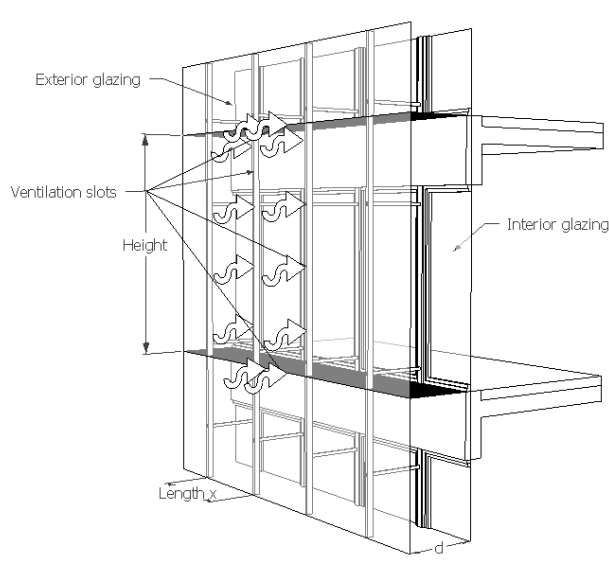

(b)

Fig. 1 Scheme of corridor type DSF naturally ventilated by a) grills; b) slots between adjacent glass panels.

In accordance with standard EN ISO 16283-3 [66] the following values have been evaluated:

$D_{2 m} \quad$ Level difference;

$D_{2 m, n T} \quad$ Standardized level difference;

$T_{20, f=1000 \mathrm{~Hz}} \quad$ Reverberation time for $f=1000 \mathrm{~Hz}$

Nine measured facades have been divided into three groups following criteria of interspace geometry as well ventilation slots types:

- Slotted DSF (cavity thickness up to $0.3 \mathrm{~m}$ );

- Corridor DSF ventilated by ventilation grills (cavity thickness from 0.5 to $1.5 \mathrm{~m}$ );

- Corridor DSF ventilated by slots (cavity thickness from 0.5 to $1.5 \mathrm{~m}$ );

The in situ sound reduction spectra (Fig. 2) show features that reflect a combination of mass law behavior (low frequency slope of 6dB/octave under mass-air-mass resonance), standing wave induced resonances in the cavity and increased glass panel - air coupling around and above the coincidence frequency. The sound insulation frequency spectra of the two slotted facades, DHTR and DBC, are very similar. Comparison of the reduced $D_{2 m, n T}$ value of the DHTR facade with the DBC façade suggests the occurrence of resonance effects in the exterior layer of the former one caused for 
frequencies above $f_{R} \approx 50 \mathrm{~Hz}$ (half wavelengths longer than 0.17 to $3.6 \mathrm{~m}$ ), as a result of standing waves in the lateral directions inside the cavity (Fig. 2a). The slope of the SR curves for the facades in the "Slotted $T F$ " and the "Corridor DSF ventilated by ventilation grills" groups tend to $9 \mathrm{~dB} /$ octave, steeper than one of the "corridor DSF ventilated by slots" group (roughly $6 \mathrm{~dB} /$ octave), which includes facades ventilated by approximately $20 \mathrm{~mm}$ thick slots between exterior glass layers. Ideally, except for resonance and coincidence effects, double wall structure exhibit a $2 \times 6=12 \mathrm{~dB}$ per octave behavior. The slope of $9 \mathrm{~dB} / \mathrm{octave}$ of the former group is somewhat lower due to the ventilation gaps. The gap in the panel on the exterior side of the cavity renders this panel ineffective in terms of sound insulation. As a result, most of the insulating effect is due to the interior panel only, explaining the lower slope, which is similar to mass-law behavior of that single panel.

The complex geometry of many DSF constructions can easily result in unwanted influences of resonances of some of their constituents. E.g. in Figure $2 \mathrm{~b}$ the $D_{2 m}$ curve at frequencies above $1 \mathrm{kHz}$ is significantly affected by structural resonances of the aluminum stripes at the outside of the facade of the SLSP building, caused by wind flowing across the facade during the measurements.

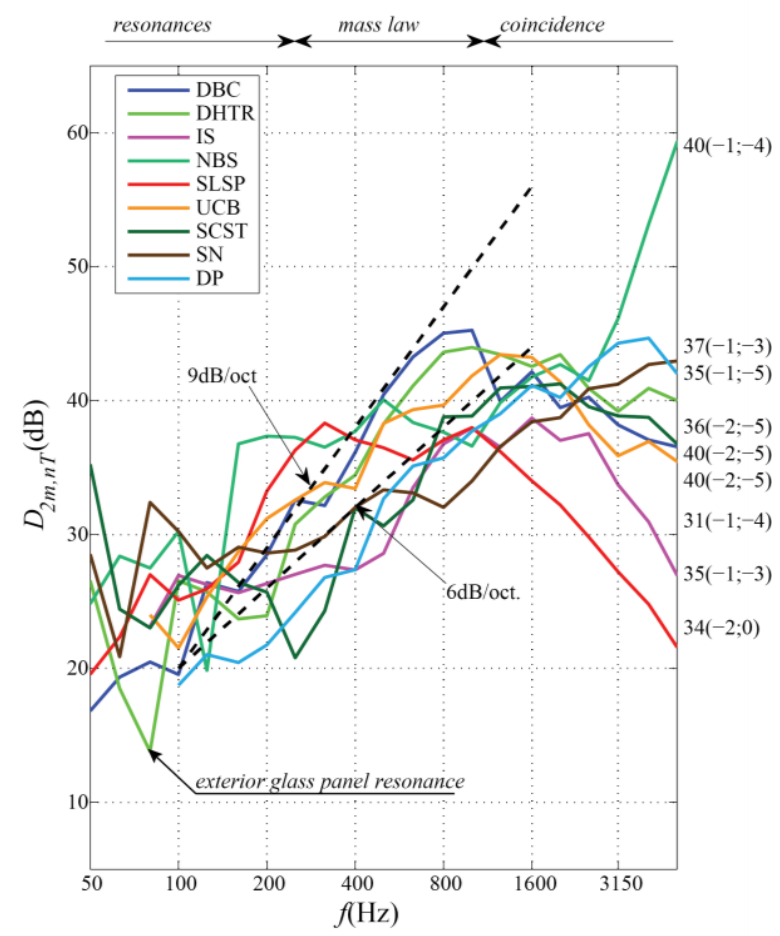

(a)

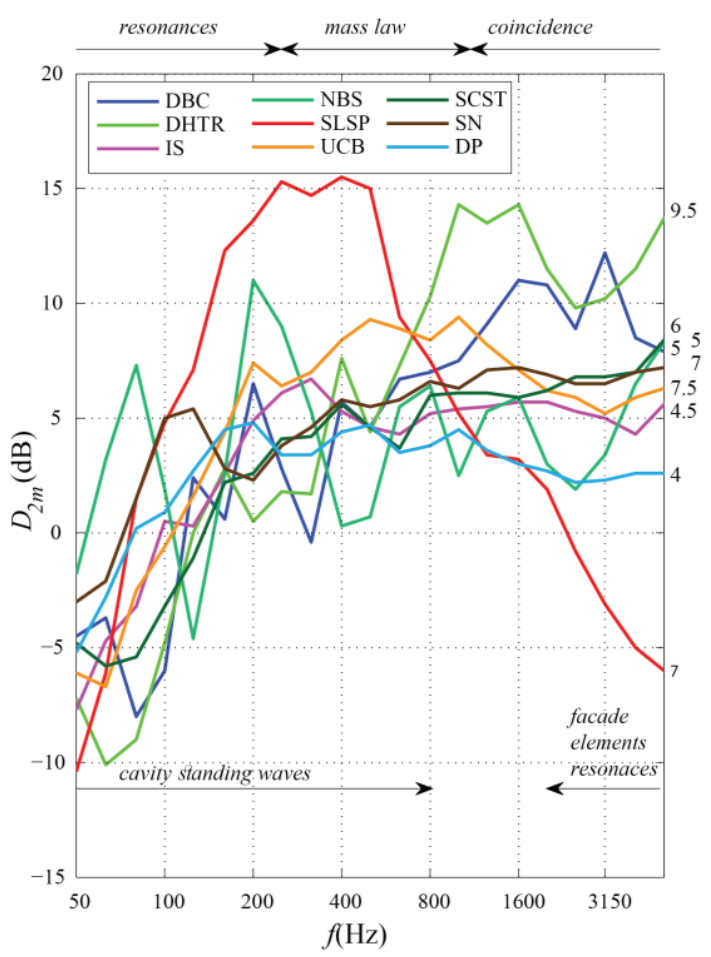

(b)

Fig. 2 Spectrally resolved sound insulation of DSF's measured in situ; a) $D_{2 m, n T}$; b) $D_{2 m}$. The single number ratings are indicated on the right hand side of the figures $\left(D_{2 m, n T, w, 100-3150 H z}\left(C ; C_{t r}\right)\right)$. 


\section{Laboratory measurements}

The laboratory measurements on the 9 different glass window DSF-like arrangements (Fig. 3) were performed in the sound transmission facility of the Laboratory of Acoustics of KU Leuven in accordance with standard ISO 10140-4 [67]. An additional microphone (a B\&K type 4165(1663259) + UA0512) was placed inside the cavity (Fig. 4b). The goal was to investigate the influence of the cavity thickness, the parallelism of the two glass panels, the absorptivity of the cavity, and the effect of ventilation slots. Two types of glass panels were used in the measurements: 12 x 1350 x $1540 \mathrm{~mm}$ single glass panel and $8.6 \times 1235 \times 1490 \mathrm{~mm}$ (442) thick laminated glass panel (two layers of $4 \mathrm{~mm}$ thick floated glass coupled by doubled layer of PVB foil). Each glass window arrangement with annotation DG consisted of a layer of $12 \mathrm{~mm}$ glass on one side and of a $8.6 \mathrm{~mm}$ laminated glass panel on the other side. As shown in Figure 3, vertical ventilation slots were created in two variants, both in combination with 8.6 laminated glass.

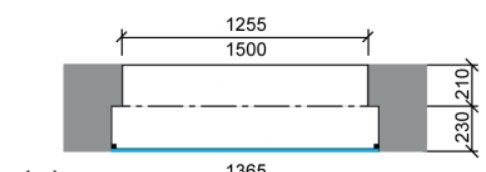

(a)

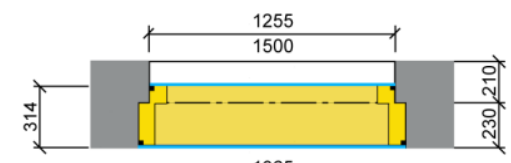

(b)

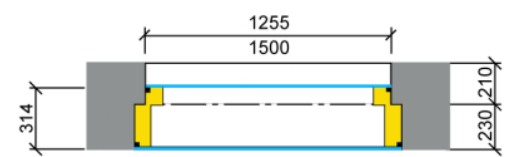

(c)
1365

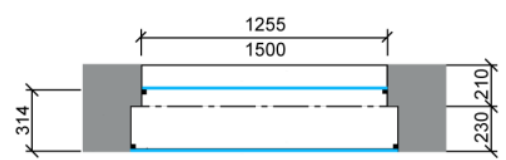

(d)

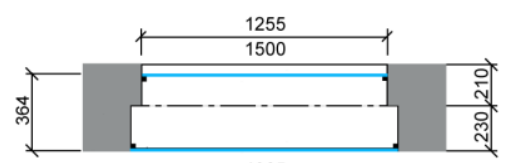

(e)

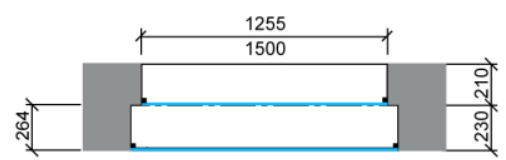

(f) $\longleftarrow \frac{1365}{1550}$

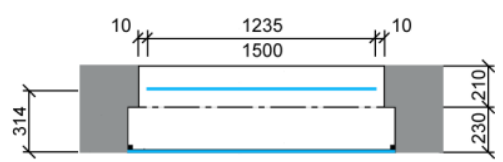

(g) $\longleftarrow \frac{1365}{1550}$

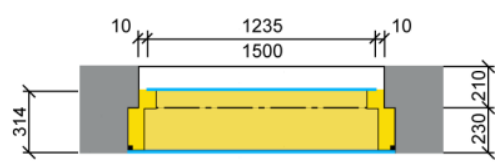

(h)

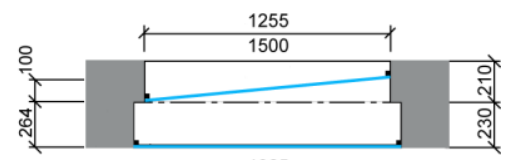

(i) $\longleftarrow \frac{1365}{1550}$

Fig. 3 Nine glass window arrangements. a) SG; b) DG314MWA; c) DG314MWTB; d) DG314; e) DG364; f) DG264; g) DG314VS; h) DG314VSTB; i) DGNP.

The meaning of the abbreviations used is as follows:

- $\quad$ SG (single glass $12 \mathrm{~mm}$ );

- DG314MWA (double glass with $314 \mathrm{~mm}$ cavity thickness and mineral wall lining all around on the edges of the window opening); 
- DG314MWTB (double glass with $314 \mathrm{~mm}$ cavity thickness and mineral wall lining on top and bottom side on the edges of the window opening Fig. 4);

- $\quad$ DG314 (double glass with 314 mm cavity thickness);

- DG364 (double glass with 364 mm cavity);

- DG264 (double glass with 264 mm cavity thickness);

- DG314VS (double glass with $314 \mathrm{~mm}$ cavity thickness and vertical ventilation slots);

- DG314VSTB (double glass with $314 \mathrm{~mm}$ cavity thickness, vertical ventilation slots and mineral wall lining just on top and bottom side);

- DGNP (double glass with nonparallel arrangement with thickness from 264 to 364 on vertical sides);

The glass panels were fastened to a massive steel frame and a wooden frame, which were rigidly mounted in the test opening, using a standard acoustic sealant, according to EN ISO 10140-1. In configurations DG314MWA, DG314MWTB, DG314VSTB the cavity absorption was enlarged by means of a $12 \mathrm{~mm}$ thick mineral wool lining (Fig. 4).

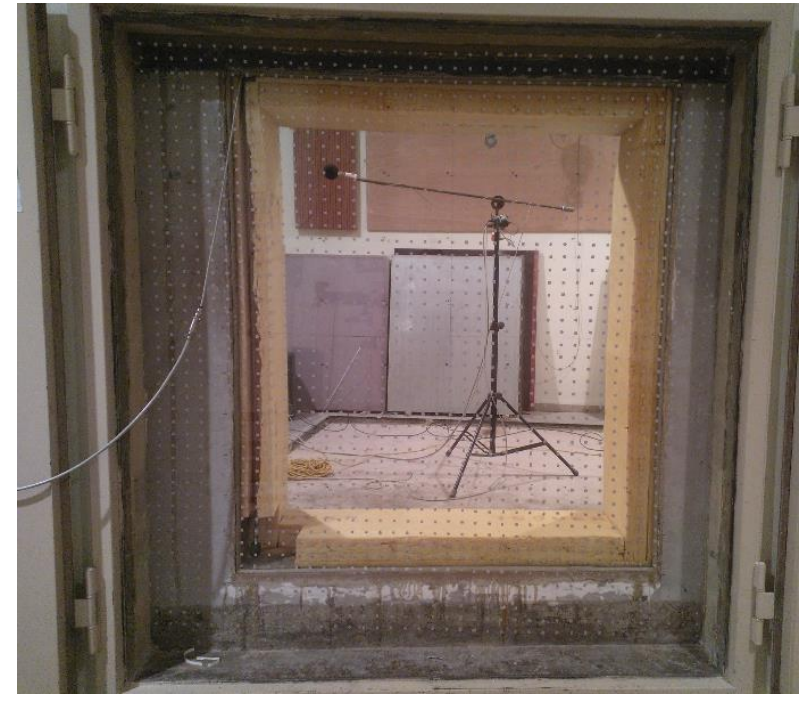

(a)

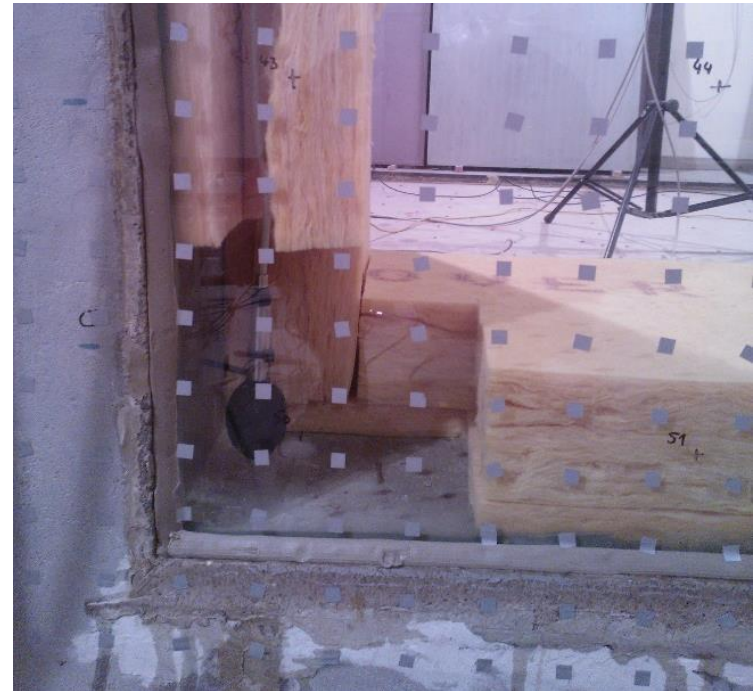

(b)

Fig. 4 a) Configuration DG314MWA; b) Detail showing the position of the intra-cavity microphone (10cm from surrounding surfaces)

In addition to the sound insulation measurements according to ISO 10140-2[68] and the measurement of the sound pressure level inside the cavity, and in order to get more insight in the sound propagation 
through the glass panel - cavity -glass panel structure, the following additional experiments were carried out.

- Mapping of the structural vibration modes of the glass panels by laser Doppler scanning vibrometry;

- Determination of the absorptivity of the acoustic absorption material inside cavity according to ISO 10140-1:2010 [69];

- Determination of the flow resistivity of the absorption material according to ISO 9053:1991 [70];

Also the room acoustic parameters of the transmission rooms were measured according to standard ISO 3382-2 [71] (Fig. 5). All devices and accessories were consistent with the standard requirements described in IEC 61672-1, IEC 61260, IEC 60942 [62, 72, 73].

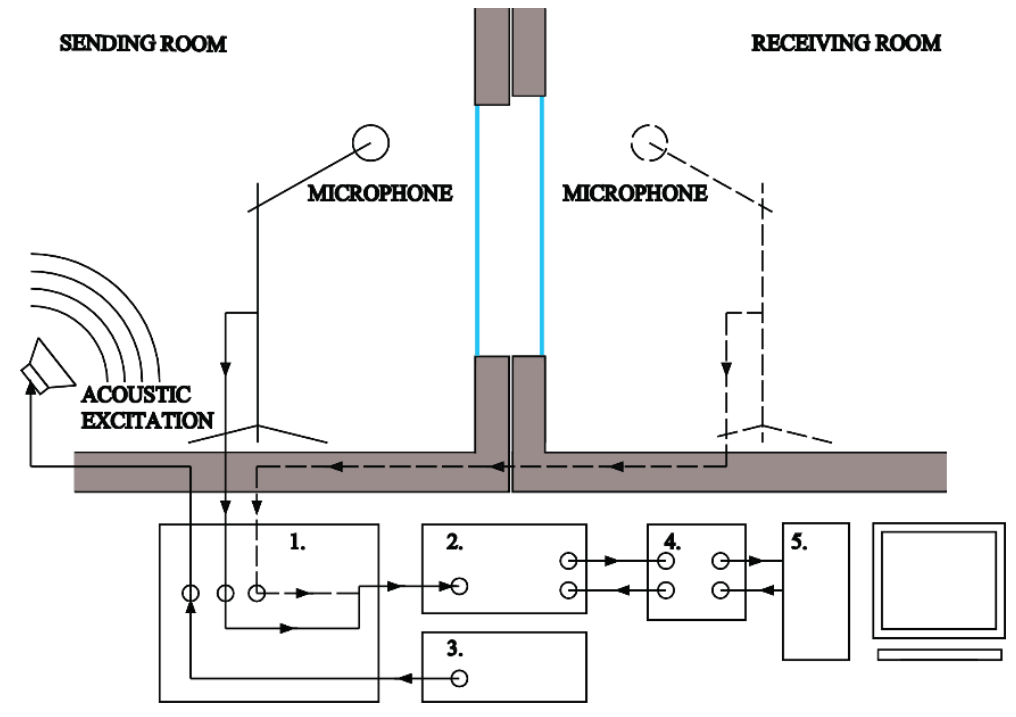

Fig. 5 Scheme of the laboratory sound insulation measurement setup; 1. Control panel; 2. Real-time frequency analyzer; 3. Pink noise generator and equalizer; 4. Transducer; 5. PC;

The airborne sound insulation was measured in the frequency range from 63 to $5000 \mathrm{~Hz}$ (Fig. 6). Four characteristics (mass law behavior, cavity resonance behavior, coincidence dip, and high frequency behavior above the coincidence frequency) can be recognized. The associated weighted sound reduction index values are listed in Table 2. Based upon measurement history, testing building elements with a significantly higher single number evaluations (as high as $R_{w}-68 \mathrm{~dB}$ ), the flanking 
paths of the test suit are considered to be low enough to ensure a correct measurement of the building elements considered in this manuscript.

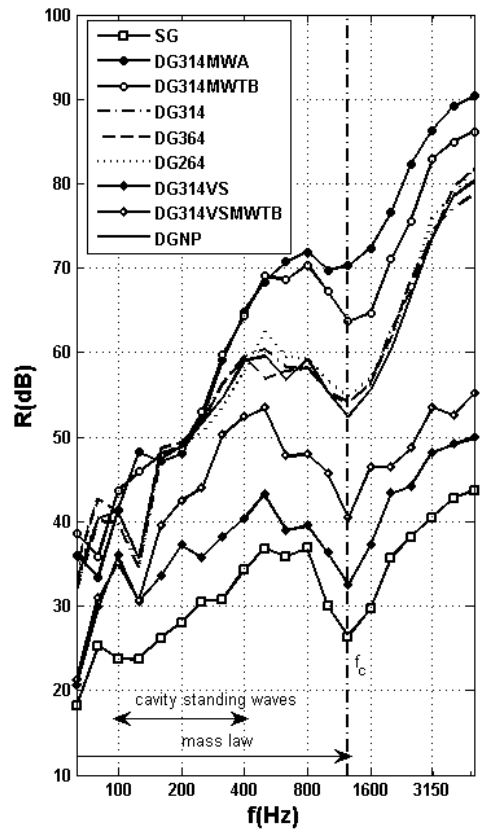

Table 2 Weighted Sound Reduction Index $\left(\underline{R}_{\underline{w}}\right)$ evaluation.

\begin{tabular}{|l|c|}
\hline Glass window arrangement & $\begin{array}{l}R_{w} \text { 100-3150Hz }\left(C ; C_{t r}\right) \\
(\mathrm{dB})\end{array}$ \\
\hline SG & $34(-3 ;-4)$ \\
\hline DG314MWA & $66(-3 ;-8)$ \\
\hline DG314MWTB & $65(-2 ;-7)$ \\
\hline DG314 & $58(-3 ;-7)$ \\
\hline DG364 & $58(-2 ;-6)$ \\
\hline DG264 & $58(-2 ;-7)$ \\
\hline DG314VS & $40(-3 ;-3)$ \\
\hline DG314VSMWTB & $47(-2 ;-4)$ \\
\hline DGNP & $57(-2 ;-5)$ \\
\hline
\end{tabular}

Fig. 6 Airborne sound insulation spectra of nine glass window arrangements.

It is known that the accuracy of in situ as well as of laboratory measurements at low frequencies is strongly influenced by the finite dimensions of the receiving room [74-77]. This is especially apparent in the low frequency range, where the acoustic modal densities of the sending and receiving rooms are too low to assure a diffused acoustic field. For a receiving room volume of less than $100 \mathrm{~m}^{3}$, standardized microphone measurements cannot achieve sufficient accuracy below $63 \mathrm{~Hz}$ [78-82]. For the acoustic insulation measurements that were performed in this study (room volume 87 $\mathrm{m}^{3}$ ) (Fig. 7), this is reflected in the increased standard deviation (STD) in the low frequency range specified according to standard EN ISO 10140-2 [83]. Reverberation time of the receiving room for middle frequency $1000 \mathrm{~Hz}$ was $T_{20, f=1000 \mathrm{~Hz}}=1.7 \mathrm{~s}$. The $S T D$ of measured reverberation time in frequencies below $280 \mathrm{~Hz}$ was higher than $0.5 \mathrm{~s}$ (from $0.5 \mathrm{~s}(f=200 \mathrm{~Hz})$ to $3.5 \mathrm{~s}(f=50 \mathrm{~Hz})$ ). This is caused by the low diffusivity in the lower frequency range, which is a common problem for transmission rooms with volume lower than $100 \mathrm{~m}^{3}$. The theoretically calculated Schroeder frequency is approximately $f=280 \mathrm{~Hz}$, what agrees with the measured data. 


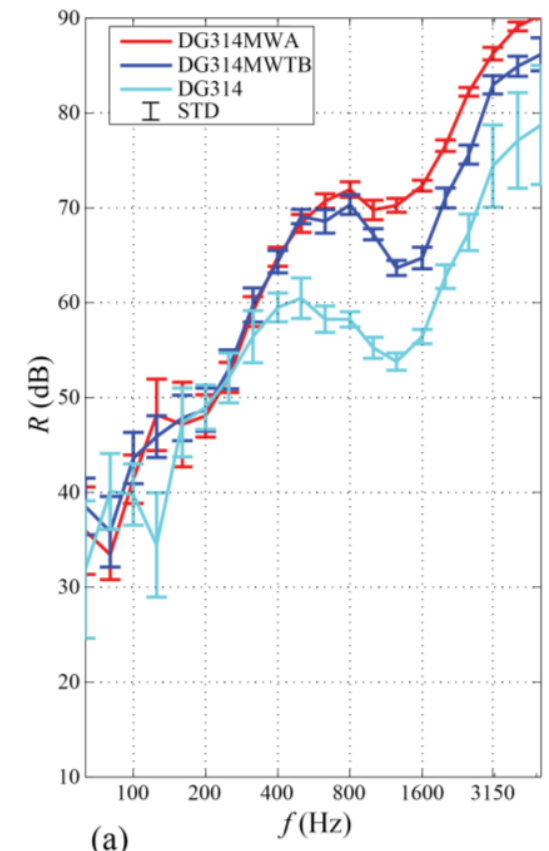

(a)

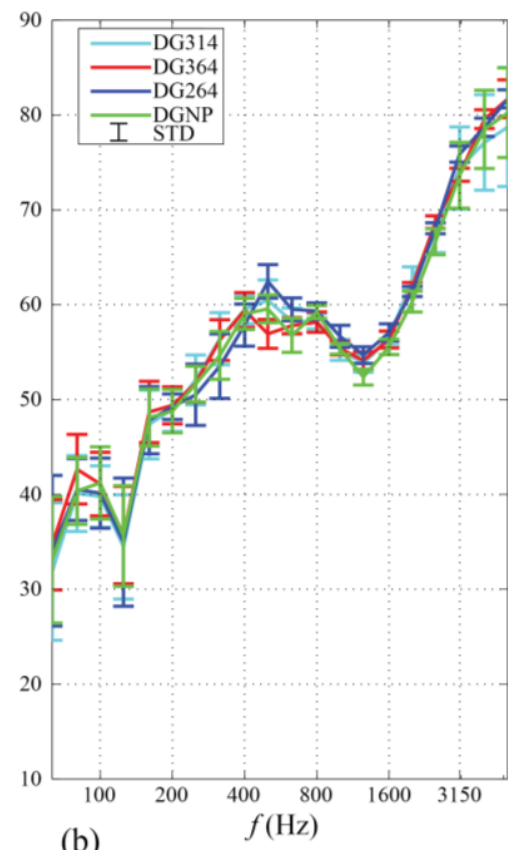

(b)

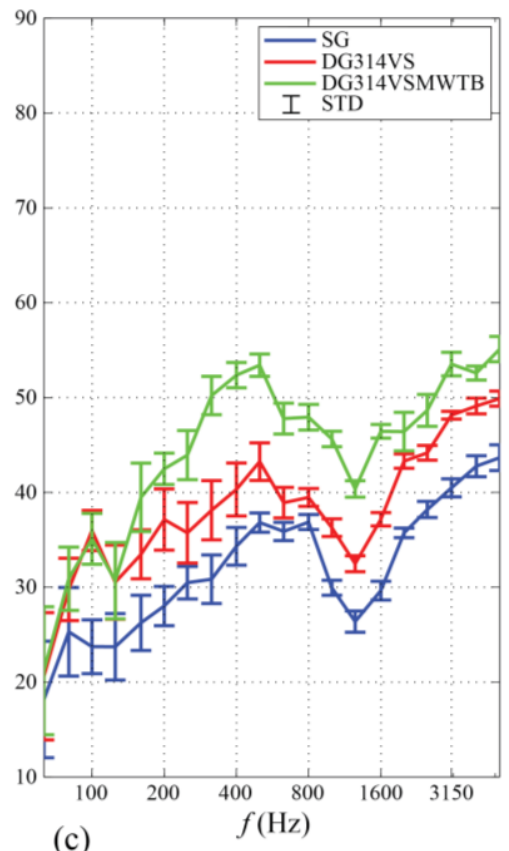

(c)

Fig. 7 Effect of different changes of the cavity on the frequency dependence of the sound reduction index; a)absorptivity change; b)shape change; c)single glass vs. double glazing with vertical slots on one of the layers. STD: measurement standard deviation.

In the absence of resonances, bending and coincidence effects, the R-spectrum of a double glass panel without ventilation slots is expected to follow a $+12 \mathrm{~dB} /$ octave mass law behavior. Fig. 7 shows that in practice the sound insulation below the coincidence frequency is effectively affected by cavity and panel bending resonances. The dips in the spectrum of the sound reduction index in different tested configurations appear to correspond with the lowest cavity resonance around $140 \mathrm{~Hz}$, for which $\lambda / 2$, half of the acoustic wavelength is close to the longest cavity dimensions $(1235 / 1540$ $\mathrm{mm})$, and around $1000 \mathrm{~Hz}$, for which $\lambda / 2$ fits the thickness of the cavity $(314 / 364 \mathrm{~mm})$.

Placing a $12 \mathrm{~cm}$ thick layer of mineral wool all around the edges of the cavity (configuration DG314MWA) improves the sound insulation around the $1100 \mathrm{~Hz}$ resonance frequency by 8 till $14 \mathrm{~dB}$ in the case of a closed cavity (DG314MWTB, DG314MWA), resulting in an overall $R_{w}$ increase of about $8 \mathrm{~dB}$. The presence of mineral wool lining on the top and bottom cavity surfaces only (alternative DG314MWTB) turns out to quench standing wave modes in the cavity sufficiently to increase $R_{w}$ by about $7 \mathrm{~dB}$. 
Interestingly, comparing configurations DG314VS and DG314VSMWTB, i.e. the situation with vertical slots (typically used for ventilation purposes) without and with mineral wool lining at the top and at the bottom of the edges, also shows a $7 \mathrm{~dB}$ increase of the $R_{w}$ when absorption is added to damp standing waves. The presence of mineral wool lining thus has almost the same influence in situations with or without vertical ventilation slots on the sides. Compared to single glass, the $R_{w}$ value of a double glass facade is $13 \mathrm{~dB}$ higher, even with open slots.

No effect is noticeable of increasing the cavity thickness from 264 to $364 \mathrm{~mm}$, with corresponding longest standing wave frequencies $2000 \mathrm{~Hz}$ and $2600 \mathrm{~Hz}$. Apparently, the effect is masked by the one of the standing wave across the longest cavity dimension.

In order to get a more detailed insight in the sound field and the standing waves phenomena, impulse response measurements [84-86] were performed, not only with a microphone in front and behind of the double glass structures, but with also in one of the bottom corners of the cavity, at $100 \mathrm{~mm}$ from the most nearby surfaces (Figures 4 and 8 ). Sine sweep excitation signal was used according to ISO 18233 [87].

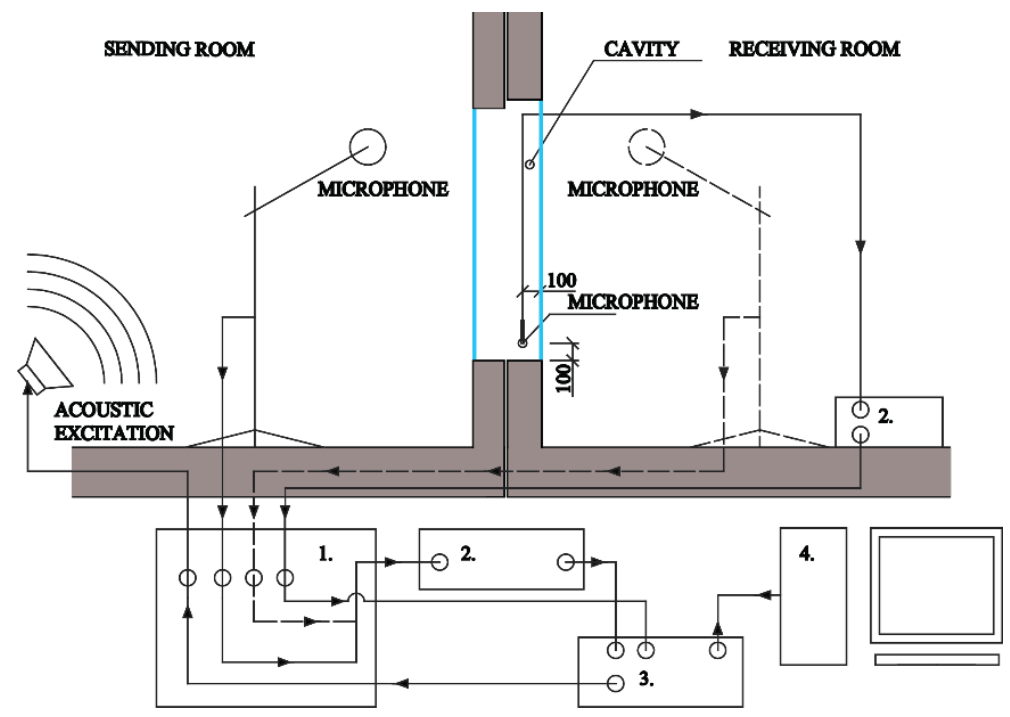

Fig. 8 Setup for determining the impulse response of double glass structures with microphones in front, behind and inside of the cavity; 1. Control panel; 2. Amplifier; 3. Transducer; 4. PC.

The resulting narrowband spectra $(30-500 \mathrm{~Hz})$ of the sound pressure level $L_{p}$ in the cavity are shown for the different configurations (Fig. 9). Theoretical estimates of the eigenmodes of the interspace cavity and the laboratory rooms, calculated as Eq. (1): 


$$
f_{n_{x}, n_{y}, n_{z}}=\frac{c}{2} \sqrt{\left(\frac{n_{x}}{L_{x}}\right)^{2}+\left(\frac{n_{y}}{L_{y}}\right)^{2}+\left(\frac{n_{z}}{L_{z}}\right)^{2}}
$$

with $L_{x}=1.37 \mathrm{~m}, L_{y}=1.558 \mathrm{~m}, L_{z}=0.264-0.364 \mathrm{~m}$ the cavity dimensions, $c=340 \mathrm{~m} / \mathrm{s}$ the speed of sound in air, an $n_{x}, n_{y}, n_{z}$ integer numbers, are shown as vertical lines. The resonances below $100 \mathrm{~Hz}$ are due to standing waves in the sending room, of which the sound field drives the one in the cavity. The spectral peaks between 100 and $350 \mathrm{~Hz}$ can be associated with cavity resonances. Above $350 \mathrm{~Hz}$, the resonances are so abundant, that, given their finite width, they are hard to distinguish. From the theoretical cavity reverberation time $T_{60, \text { cavity }}=0,2 \mathrm{sec}[88]$ and its volume $V_{\text {cavity }}=0,56-0,79 \mathrm{~m}^{3}$, the Schröder frequency $[89,90]$, above which the sound field in the cavity can be considered as diffuse, equals $1200 \mathrm{~Hz}$. Changing the interspace shape from a parallel glass panel configuration (DG314) to a nonparallel one (DGNP) only slightly changes the resonance frequencies of the cavity. The effect of introducing a cavity lining of mineral wool reduces the overall sound pressure level by 8 to $10 \mathrm{~dB}$. At the standing waves frequencies, the influence is up to about $20 \mathrm{~dB}$. Opening the front facade, as in the configurations with vertical slots, increases the sound pressure level substantially from $50 \mathrm{~Hz}$ on and above, with about $20 \mathrm{~dB}$.

Modal analysis of glass plates fixed in testing opening was performed for each of the setups. Amplitude peaks corresponding to structural modes of the $2^{\text {nd }}$ order are clearly present (Fig. 9). The first order modes are below $30 \mathrm{~Hz}$, out of displayed range. The structural resonances of the glass are indicated by S (S1-8.6 mm laminated glass plate with vertical slots where $f_{11}=18.2 \mathrm{~Hz}$ and $f_{21}=39.2$ $\mathrm{Hz}$; S2- $8.6 \mathrm{~mm}$ laminated glass plate fixed around the perimeter where $f_{11}=25.3 \mathrm{~Hz}$ and $f_{21}=48.4 \mathrm{~Hz}$; S3- $12 \mathrm{~mm}$ glass plate fixed around the perimeter where $f_{1 I}=25.6 \mathrm{~Hz}$ and $f_{2 l}=59.8 \mathrm{~Hz}$ ) (Fig. 9). Some glass plate resonances are masked by cavity resonances. 

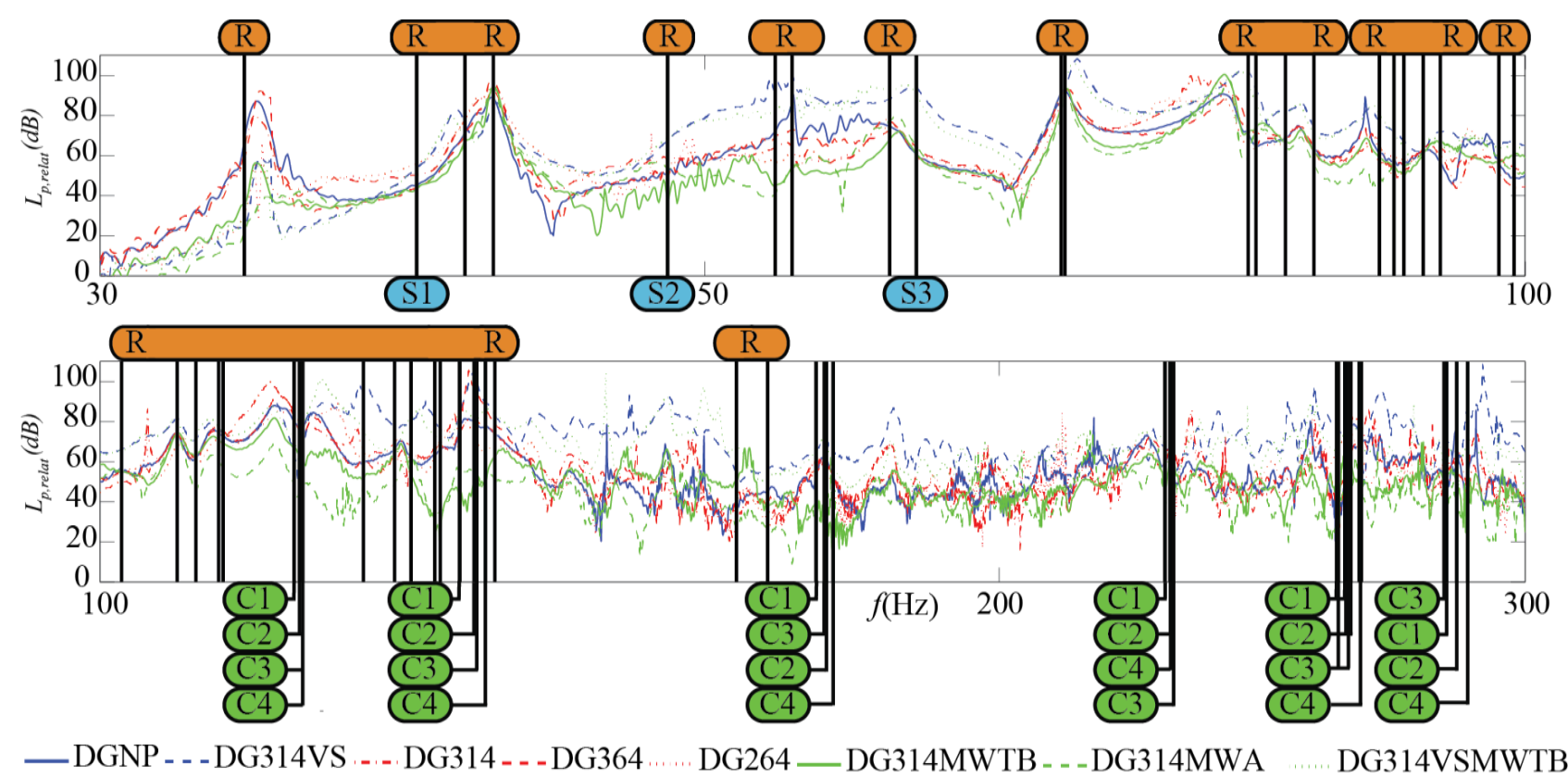

Fig. $8 L_{p}$ spectrum inside specimen cavity. Freq. range 30- $100 \mathrm{~Hz}$ (up); 100-500 Hz (bottom); R- Sending room resonances; S- Glass plate $2^{\text {nd }}$ mode natural resonances (S1- 442 laminated glass plate with vertical slots; S2- 442 laminated glass plate fixed around the perimeter; S3- 12mm glass plate fixed around the perimeter ).

\section{Sound insulation of double glass building elements: comparison between different models and experimental results}

Models of double wall constructions typically take into account the boundary conditions, the dimensions, the material properties, the cavity absorptivity, the angle of incidence of the incoming sound wave, etc. In the case of a transparent wall, structural rigidity is realized by stiffening elements, such as frames. In this section, a number of analytical prediction models are compared with the measurement data (Fig. 10-11). Models of the following authors are considered: Fahy (three models) [35, 91], London [92], "technical method" [93], Sharp [33] and the Brekke [94]. Rindel [95] predicted the sound insulation in walls with small openings (ventilation slots).

Three different models by Fahy are considered. The first model assumes perpendicular incidence and infinite double walls without absorptive material inside. The variables in this method are the mass of the panels, the mechanic loss factor, the damping, the stiffness, the cavity thickness, the speed of the sound and the density of air. Also mass-spring- mass resonance and natural resonances of each layers are included. Also the second model assumes perpendicular incidence, but it 
takes into account the presence of absorptive material inside the cavity. The third model extends the previous one, by allowing an oblique angle of incidence. Fitting of the experimental results by this model are not satisfactory (Fig. 11). This is most likely a consequence of the non-realistic assumption of a single angle of incidence (in our simulation, we assumed an angle of $45^{\circ}$ ) and assumption due to the infinite window dimensions.

The model proposed by London (Fig. 10) was originally designed for unbounded double walls without absorptive material inside the cavity. Also this calculation model neglects structural resonances and coincidence resonances of the panels. The cavity resonance frequency, the angle of incidence (for the frequency range below the cavity resonance they consider direct sound field, above the cavity resonance a diffuse sound field is considered), the mass, the approximated phase coefficient, the density of air, the atmospheric pressure and the speed of the sound are variables in this model. We have applied this model for the 3 closed DSF configurations without absorbing material: DG314, DG364 and DG264. After neglecting of structural resonances, the slopes of London's model results of are in acceptable agreement ( $6 \mathrm{~dB} /$ oct below and $18 \mathrm{~dB} /$ oct above cavity resonance frequency), the calculated $R$-spectra underestimated the experimental ones, probably due to the calculations assuming a unbounded infinite media outside of the cavity.

The "technical method", which was mainly designed for double walls (cavity thickness below $200 \mathrm{~mm}$ ) with absorption inside the cavity, was used to predict the airborne sound insulation for configurations DG314MWA, DG314MWTB, DG314, DG364, DG264. The sound insulation, the stiffness and the coincidence frequencies of partition walls, the cavity thickness and the damping and mass-spring-mass resonance of the wall are taken as variables. Figure 10 shows that the best correspondence was achieved for the DSF configuration DG314 without absorption. This seems paradoxal, but can be explained that the method was designed for infinite walls, with absorption only along the walls. Model takes into account critical and cavity resonance as well. In range below cavity resonance, shape of calculated $\mathrm{R}$ spectrum nicely follows shape of measured data results. In spectrum range above cavity resonance, the slope is by $10 \mathrm{~dB} / \mathrm{oct}$ lower in comparison to measured data. 
An empirical model by Sharp has been derived from a large database of double wall laboratory measurements. The model assumes an unbounded infinite wall filled with absorptive material, assuming a diffuse acoustic field in the wall cavity. The model variables of this mass-spring-mass model are: the cavity thickness, the airborne sound insulation and the mass of the partition walls, and the stiffness and damping of the wall cavity (spring). Sharp's model gives a reasonably good correspondence nicely follows shape of measured values, except for a too weakly pronounced dip at the main cavity resonance at $1000 \mathrm{~Hz}$ and resonance caused by size of testing specimen at $140 \mathrm{~Hz}$ (Fig. 10).

The same holds for the model by Brekke, which was developed for bounded double walls with absorptive material lining all around on the edges of the wall cavity (Fig. 10). This model was developed based on SEA models. The resulting calculation assumes sound insulation of partition walls, absorption coefficient of absorptive material, cavity circuit, thickness and surface of the wall. In range below cavity resonance, shape of calculated $\mathrm{R}$ spectrum nicely follows shape of measured data results. However in spectrum range above cavity resonance, the slope is appropriate but with underestimated values about $6 \mathrm{~dB}$.

For this study, the model of Sharp and the one of Brekke yield the best correspondence with the measurements. In view of that, we have implemented a combination of both, also incorporating the approach by Rindel to include the deterioration of the sound insulation due to a ventilation slit. A reasonably good results for spectrum above cavity resonance was obtained in Brekke+Rindel model, provided that the slot size in the model was not set equal to the average value of the DSF, but to the smallest one (Fig. 11). In the part of the spectrum below cavity resonance, calculated results were underestimated by $6 \mathrm{~dB}$. 

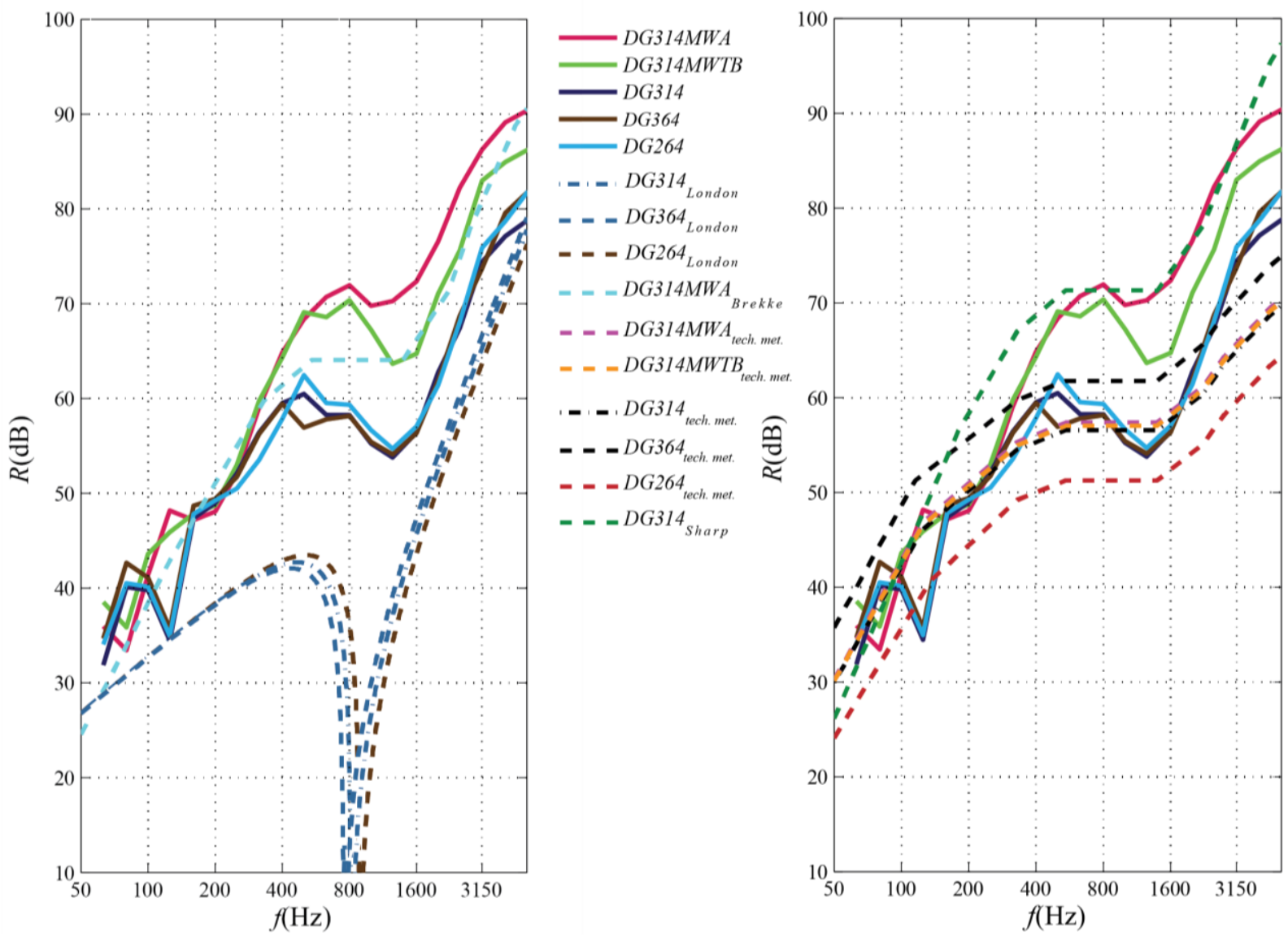

Fig. 9 Comparison of the models of London vs. Brekke (left) and Technical method vs. Sharp (right) with the measured sound insulation spectra. 

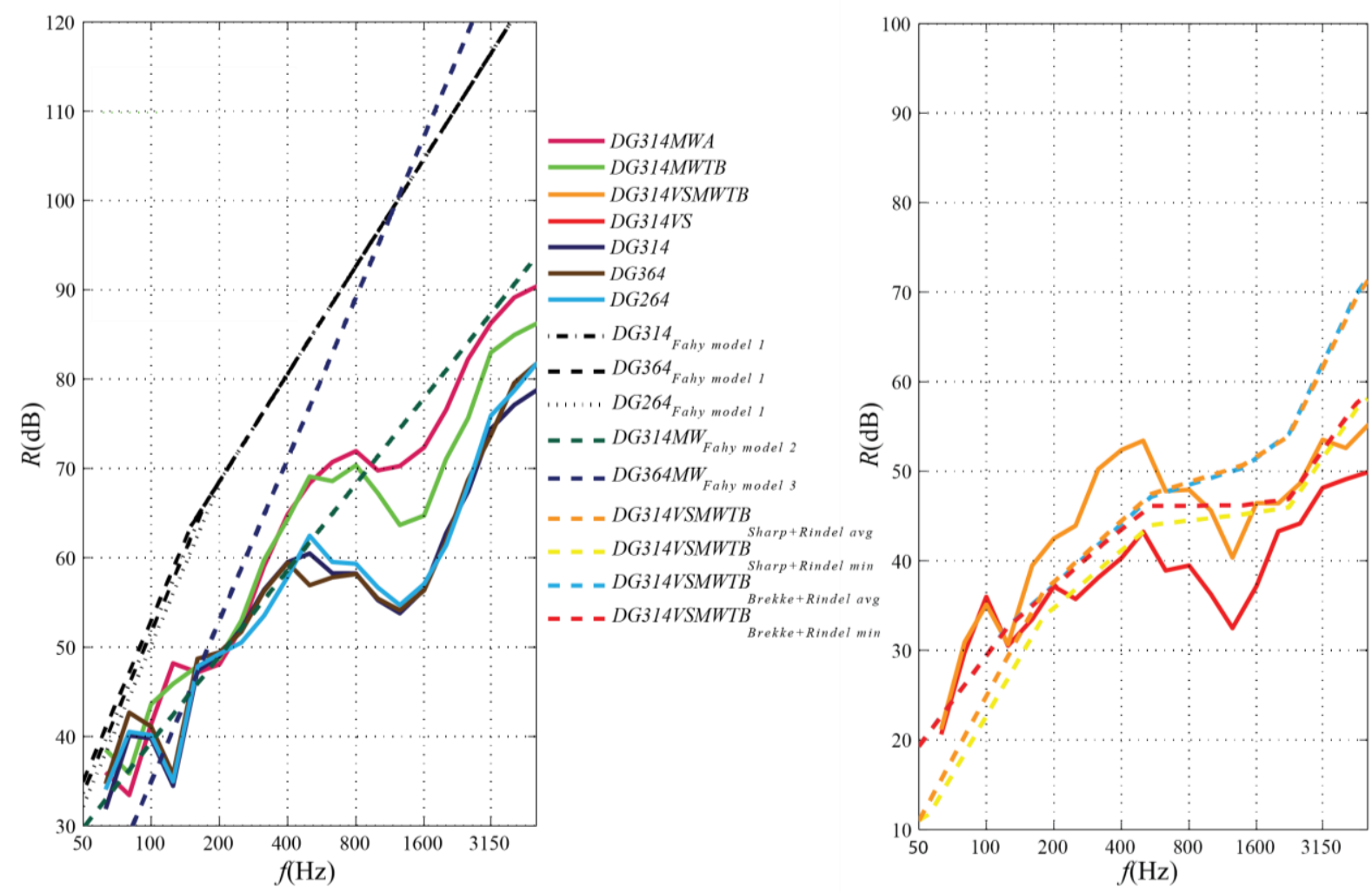

Fig. 10 Comparison with experimental data of predictions by the Fahy models (left)and combinations of models Sharp+

Rindel and Brekke+Rindel (right).

\section{Prediction of the sound insulation of naturally ventilated double skin}

\section{facades}

The incentive behind this work was to create a simple prediction method for the calculation of sound insulation spectra of naturally ventilated DSF, for use in an engineering environment. All mentioned models above were created for double leaf walls consisting of simple layers. In the current work, the idea was to predict the sound insulation of DSF's based on the responses of the individual parts of the facade. In an attempt to tune the modeling to double skin facades, and inspired by the approach of Blasco [48], we have determined the individual sound insulation of each panel $\left(R_{l}\right.$ and $\left.R_{2}\right)$ and of each element within the layers by means of standard approaches Eq. (2), and incorporated those in an expression for the combined sound insulation via [93] (Fig. 12b):

$$
R_{i}=10 \cdot \log \frac{S_{i, 1}+S_{i, 2}+S_{i, s} \ldots . S_{i, j}}{S_{i, 1} \cdot 10^{-0.1 \cdot R_{i, 1}}+S_{i, 2} \cdot 10^{-0.1 \cdot R_{i, 2}}+S_{i, s} \cdot 10^{-0.1 \cdot R_{i, s}}+\ldots . S_{i, j} \cdot 10^{-0.1 \cdot R_{i, j}}}
$$

with: 
$i \quad$ index of interior DSF layer (e- in exterior layer case) (Fig. 12b);

$j \quad$ index of element in a layer (Fig. 12b);

$s \quad$ index of ventilation slot (Fig. 12b );

$S_{i, j} \quad$ surface of element or slot $i, j\left(\mathrm{~m}^{2}\right)$;

$R_{i, j} \quad$ partial sound insulation of element $i, j(\mathrm{~dB})$

Ventilation slots (slot sizes are specified in Table 1) were modeled as gaps in the exterior layer $\left(R_{i, s}\right)$ as proposed in [95] as follows Eq. (3):

$$
R_{i, s}=10 \log \left(1.09 \cdot 10^{-4} \cdot\left(\frac{\sqrt{S}}{2}\right)^{2} \cdot f^{2}+0,72\right)
$$

Blasco [48] divided the sound insulation spectra to two parts, below and above the half wavelength matching resonance frequency of the cavity ( $f_{0}=c / 2 d$, with $d$ the cavity thickness). He then determined the DSF layer (exterior or interior) with the lowest sound insulation, in order to estimate the total sound insulation. Here, we determine which of both DSF layers (the exterior or interior one) has the most dominant contribution in sound insulation (denoted by $R_{\max }$ ), and consider three frequency ranges:
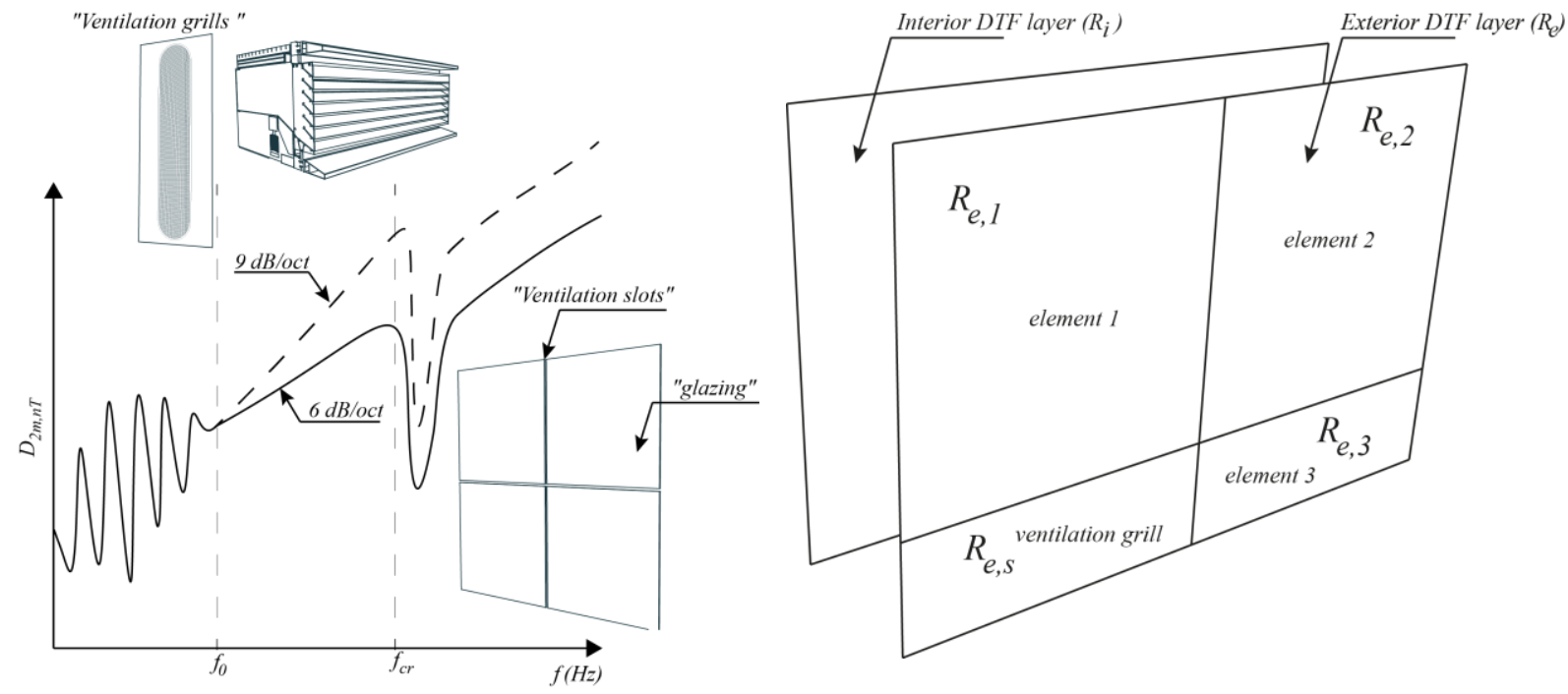

(a)

(b) 
Fig. 11 Schematic representation of the division of the spectrum into different ranges, in which the sound insulation behavior is dominated by different ventilation mechanisms (a) and of the implemented combination of elements to predict the total sound insulation (b).$f_{0^{-}}$cavity resonance frequency; $f_{c r}$-coincidence frequency;

- The frequency range with sound insulation behavior dominated by transmission enhancement due to cavity resonances (below frequency $f_{0}$ ). In this frequency range, the sound insulation is determined by the distance between the parallel DSF layers. The sound insulation is approximated by the sum of the individual insulations of the two panels, decremented by $4 \mathrm{~dB}$ Eq. (4):

$$
R_{\left(f \leq f_{0}\right)}=R_{1}+R_{2}-4 d B
$$

In Blasco's model sound insulation in the frequency range below $f_{0}$ is counted as $\left(R_{\min }+10\right.$ $\mathrm{dB}$ ). For frequencies higher than $f_{0}$ Blasco's model uses $R_{1}+R_{2}$ (no further distinction in frequency ranges are made in his model).

- The frequency range with sound insulation behavior dominated by the transmission of sound via the ventilation slots. More specifically, this is the range between $f_{0}$ and $f_{c r}$, the coincidence frequency of the exterior glass panel, which is given by Eq. (5) [35]:

$$
f_{c r}=\frac{c^{2}}{1.8 \cdot h \cdot c_{l}}
$$

with:

$$
\begin{array}{ll}
f_{c r} & \text { coincidence frequency }(\mathrm{Hz}) ; \\
c & \text { speed of sound in air }(\mathrm{m} / \mathrm{s}) ; \\
h & \text { thickness of specimen }(\mathrm{m}) ; \\
c_{l} & \text { longitudinal speed of sound in specimen }(\mathrm{m} / \mathrm{s}) ;
\end{array}
$$

Here, we have assumed that for ventilation by open slots, the sound insulation of the exterior window is to an important extent neutralized, reducing the overall sound insulation by 6 $\mathrm{dB} /$ octave compared to the serial effect of two panels with mass-law behavior $(+12$ 
$\mathrm{dB} /$ octave). For ventilation by a mesh or a grill, we have assumed an intermediate reduction by $3 \mathrm{~dB} /$ oct compared to two panels in series (see chapter 2) Eq. (6). The impact of ventilation elements was taken into account generally in the prediction model. Influences of wave diffraction are counted only partially by Eq. (3). However, the diffraction influence is not that significant in this case. The model was designed for facade sound insulation with closed windows and assumed diffuse sound fields in the frequency range where the diffraction plays an important role. In total, the transmission loss does not take into account the position of the ventilation element.

$$
R_{\left(f_{0} \rightarrow f_{c r}\right)}=R_{\left(f_{0}\right)}+6 \text { or } 9 \mathrm{~dB} / \text { oct }
$$

- The frequency range above the coincidence frequency of the external wall. For these high frequencies, even small openings in the exterior wall are neutralizing the insulating effect of the exterior glass panel, reducing the overall acoustic insulation to Eq. (7):

$$
R_{\left(f_{c r} \rightarrow f\right)}=R_{\max }+6 d B
$$

Final step of calculation is implementation of $R$ spectrum into $D_{2 m, n T}$ evaluation, to achieve results comparable with measured data from in situ measurements Eq. (8).

$$
D_{2 m, n T}=R+10 \cdot \log \frac{0.32 \mathrm{~V}}{S_{s}}
$$

with:

$V \quad$ volume of receiving room $\left(\mathrm{m}^{3}\right)$

$S_{s} \quad$ Area of the specimen $\left(\mathrm{m}^{2}\right)$

The presented prediction model was applied for slotted and corridor type DSF's, and single rating values are compared with the experimental data in Table 3 (single number ratings). Plots of sound insulation spectra of representative facades for each measured types (slotted DTF, corridor DTF ventilated by grills and corridor DTF ventilated by slots) are shown in Figure 13. 
Table 3 Comparison between predicted and measured single number ratings of the sound insulation of the different DSF samples

\begin{tabular}{|c|c|c|c|c|c|c|c|c|c|}
\hline & \multicolumn{2}{|c|}{ Slotted DSF } & \multicolumn{4}{|c|}{ Corridor DSF ventilated by grills } & \multicolumn{3}{|c|}{ Corridor DSF ventilated by slots } \\
\hline Name & $\overline{\mathrm{DBC}}$ & $\overline{\text { DHTR }}$ & NBS & SLSP & $\mathrm{UCB}$ & IS & SCST & $\overline{\mathrm{SN}}$ & $\overline{\mathrm{DP}}$ \\
\hline $\begin{array}{l}D_{2 m, n T, w \text { (in situ) }}(C ; \\
\left.C_{t r}\right)(\mathrm{dB})\end{array}$ & $\begin{array}{l}40 \quad(- \\
2 ;-5)\end{array}$ & $\begin{array}{l}40 \quad(-2 ;- \\
5)\end{array}$ & $\begin{array}{l}40 \quad(-1 ;- \\
4)\end{array}$ & $\begin{array}{l}34 \quad(-2 ; \\
0)\end{array}$ & $\begin{array}{l}39(-1 ;- \\
3)\end{array}$ & $\begin{array}{l}35(-1 ; \\
-3)\end{array}$ & $\begin{array}{l}36(-2 ;- \\
5)\end{array}$ & $\begin{array}{l}37(-1 ;- \\
3)\end{array}$ & $\begin{array}{l}35(-1 ;- \\
5)\end{array}$ \\
\hline $\begin{array}{l}D_{2 m, n T, w \text { (predict) }} \quad(C ; \\
\left.C_{t r}\right)(\mathrm{dB})\end{array}$ & $\begin{array}{l}38(-2 ; \\
-7)\end{array}$ & $\begin{array}{l}38(-2 ;- \\
7)\end{array}$ & $\begin{array}{l}39(-1 ;- \\
4)\end{array}$ & $\begin{array}{l}42(-1 ;- \\
6)\end{array}$ & $\begin{array}{l}38(-1 ;- \\
4)\end{array}$ & $\begin{array}{l}35(-2 ;- \\
6)\end{array}$ & $\begin{array}{l}36 \quad(-1 ;- \\
4)\end{array}$ & $\begin{array}{l}37(-2 ;- \\
5)\end{array}$ & $\begin{array}{l}34 \quad(-1 ;- \\
4)\end{array}$ \\
\hline
\end{tabular}

The proposed model predicts the sound insulation sound insulation spectra determined by the in situ measurements substantially better than the one of Blasco with most residues smaller than $5 \mathrm{~dB}$, and single value predictions within $1 \mathrm{~dB}$ from the experimental ones, except for the SLSP.

Due to the rather low excitation levels during the in situ measurements, the signal to noise ratio in the SLSP configuration was poor, impeding a reliable analysis.

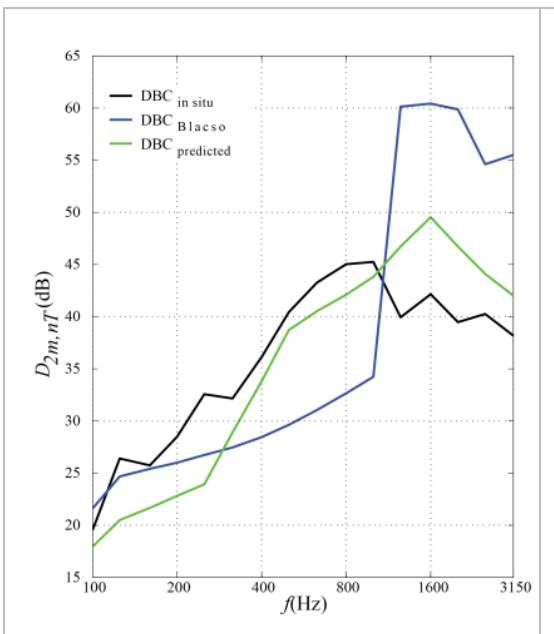

(a)

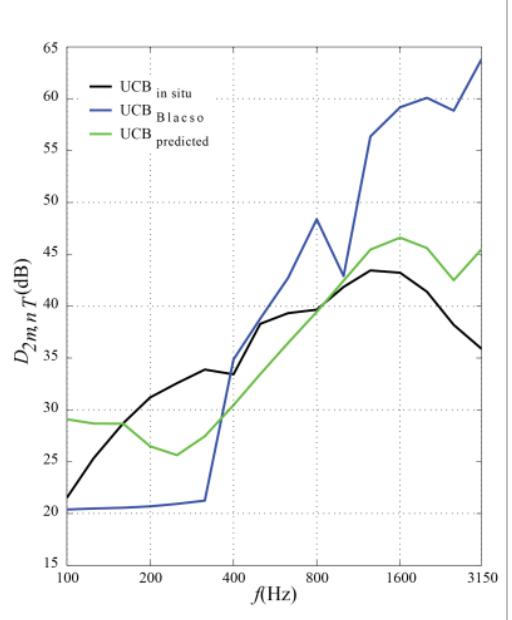

(b)

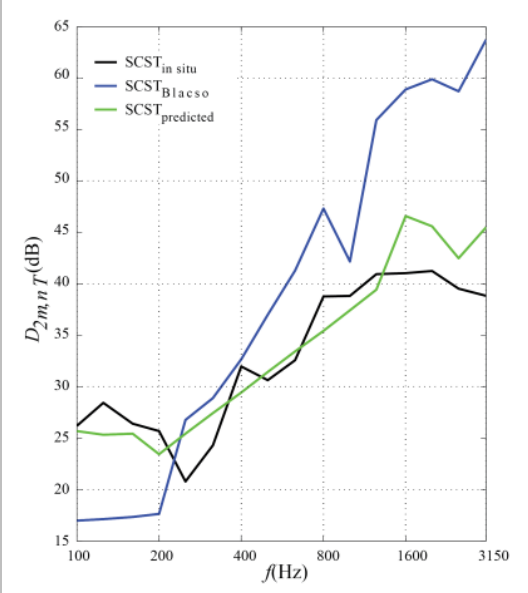

(c)

Fig. 12 Comparison between predicted and in situ measured sound insulation spectra for three different DSFs. a) Slotted DSF; b) Corridor DSF ventilated by grills; c) Corridor DSF ventilated by slots.

\section{Conclusion}

Sound insulation measurements were performed on 9 different facades in situ and 9 double glass arrangements in the laboratory. 
From the in situ measurements it was found that the sound insulation of DSFs is substantially affected by ventilation slots and acoustic resonances of the cavity. Compared to a single glass panel, a double skin facade with an exterior window with open slots yields a 5 to $7 \mathrm{~dB}$ better $R_{w}$ value. Based on the measured data, it can be inferred that increasing the width of the DTF cavity has a positive impact on the facade sound insulation, because the insulation deteriorating cavity resonance shifts to lower frequencies, which are less audible. The use of an appropriate distribution of ventilation grills (sufficiently far apart) in combination with absorptive material can yield a substantially better acoustic insulation compared to an open slot.

Laboratory measurements were carried out with special focus on the importance for the sound insulation of DSFs of the thickness and shape of the cavity, as well as on the presence and location of absorptive material in the cavity. Although increasing the cavity thickness (by 16\% from $314 \mathrm{~mm}$ to $364 \mathrm{~mm}$ ) and shape (non-parallelism of $50 \mathrm{~mm}$ ) are known to change related cavity resonance frequencies, the effect on the sound insulation spectrum was negligible in comparison with the standing wave that fits in the longest cavity dimension. The importance of the latter was also illustrated by the strong effect of placing absorbing material along the sides of the cavity on the resonance dip in the insulation spectrum, and on the SRI (7-8 dB), not only for the closed but also for the open cavity. In particular, below the coincidence frequency $(1000 \mathrm{~Hz})$, placement of absorptive material increases the slope of the sound insulation curve slope by about $+4 \mathrm{~dB} /$ octave, both for the open and closed cavity. The similar effect for the closed cavity confirms that the standing wave along the longest dimension of the cavity is hardly affected by the ventilation slots. Nevertheless, although a ventilated layer with $10 \mathrm{~mm}$ wide vertical gaps on both sides of the exterior layer increased the $R_{w}$ with about $6 \mathrm{~dB}$ in comparison with a single glass panel, the $R_{w}$ value was almost $20 \mathrm{~dB}$ less in comparison with the fully closed exterior wall, reflecting substantial changes all over the spectrum.

A simplified prediction model to calculate the sound insulation of naturally ventilated double skin facade was introduced. The analytical model is based on laboratory and in situ measurements and works well in the middle and high frequency range, with predicted single rating sound insulation values as close as $1 \mathrm{~dB}$ to experimental values. The low frequency insulation still remains difficult to 
predict, due to the occurrence of standing waves in the intermediate space, and due to structural resonances. The prediction model also generally accounts for the presence of air ventilation, which is commonly used in DSF's. Although the model was designed for facades with closed windows, the diffraction influence caused by vents was neglected: in the frequency range where the diffraction plays role, a diffuse sound field was assumed. The prediction model can be used as engineering tool for rough DTFs sound insulation in practice.

\section{Acknowledgements}

This work has been supported by COST Action TU1303, VEGA no.1/0358/13, VEGA no.1/0286/15, University Science Park of STUBA (ITMS 26240220084), the National Scholarship Programme of the SR for the Support of Mobility of Students, PhD Students, University Teachers and Researchers. The authors also acknowledge financial support by the European Commission, (H2020MSCA-RISE-2015 project 690970, "PAPABUILD". Special thanks goes to Dušan Dlhý, Willy Bruyninckx and Geert Dierckx for their assistance during measurements.

\section{References}

[1] Kim S., Lee J. H., Moon J. W.: Performance evaluation of artificial neural network-based variable control logic for double skin enveloped buildings during the heating season. Build Environ, 2014. 82: p. 328-338.

[2] Gan G. H.: Impact of computational domain on the prediction of buoyancy-driven ventilation cooling. Build Environ, 2010. 45(5): p. 1173-1183.

[3] Nore K., Blocken B., Thue J. V.: On CFD simulation of wind-induced airflow in narrow ventilated facade cavities: Coupled and decoupled simulations and modelling limitations. Build Environ, 2010. 45(8): p. 1834-1846.

[4] Chen H.-T., Lee S.-K.: Estimation of heat transfer characteristics on the hot surface of glass pane with down-flowing water film. Build Environ, 2010. 45: p. 11.

[5] Chow W. K.: Performance-based approach to determining fire safety provisions for buildings in the Asia-Oceania regions. Build Environ, 2015. 91: p. 127-137. 
[6] Mingotti N., Chenvidyakarn T., Woods A. W.: The fluid mechanics of the natural ventilation of a narrow-cavity double-skin facade. Build Environ, 2011. 46(7): p. 1523-1523.

[7] Stec W. J., van Paassen A. H. C., Maziarz A.: Modelling the double skin facade with plants. Energy and Buildings, 2005. 37(5): p. 419-427.

[8] Davis M., Hirmer S.: The potential for vertical gardens as evaporative coolers: An adaptation of the 'Penman Monteith Equation'. Build Environ, 2015. 92: p. 135-141.

[9] Leea P. J., Kima Y. H., Jeona J.Y., Song K. D.: Effects of apartment building facade and balcony design on the reduction of exterior noise. Build Environ, 2007. 42: p. 3517-3528.

[10] Sakamoto S., Aoki A.: Numerical and experimental study on noise shielding effect of eaves/ louvers attached on building facade. Build Environ, 2015. 94: p. 773-784.

[11] Lai C.M., Hokoi S.: Solar façades: A review. Build Environ, 2015. 91: p. 152-165.

[12] Blanco J. M., Arriaga P., Rojí E., Cuadrado J.: Investigating the thermal behavior of doubleskin perforated sheet façades: Part A: Model characterization and validation procedure. Build Environ, 2014. 82: p. 50-62.

[13] Huckemann V., Kuchen E., Leao M., Leao E. F.T.B. : Empirical thermal comfort evaluation of single and double skin façades. Build Environ, 2010. 45: p. 976-982.

[14] Hongisto V.: Airborne sound insulation of wall structures- measurement and prediction. methods, in Laboratory of Acoustics and Audio Signal Processing. 2000, Helsinky University of Technology.

[15] Hongisto V.: Sound Insulation of Double Panels - Comparison of Existing Prediction Models. Acta Acust, 2006. 92: p. $61-78$.

[16] Hongisto V., Lindgren M., Helenius R.: Sound insulation of double walls - An experimental parametric study. Acta Acust, 2002. 88(6): p. 904-923.

[17] Muellner H., Freyb A. , Humera C.: Sound insulation properties of building elements, considering the frequency range below $100 \mathrm{~Hz}$, Euronoise 2008. 2008, EAA: Paris.

[18] Stani M. M., Muellner H., Plotizin I.: Sound Insulation of Plasterboard Walls and Airflow Resistivity: An Empirical Examination with Respect to Practical Applications, Forum Acusticum 2005, Budapest. 
[19] Beranek L. L., Work G. A. : Sound transmission through multiple structures containing flexible blankets. JASA, 1949. 21: p. 419-428.

[20] London A.: Transmission of reverberant sound through double walls. JASA. 1950. 22: p. 270279.

[21] White P. H., Powell A. : Transmission of random sound and vibration through a rectangular double wall. JASA, 1966. 40: p. 821-832.

[22] Lyon R. H., Maidanik G. : Power flow between linearly coupled oscillators. JASA, 1962 34: p. 623-639.

[23] Mulholland K. A., Parbrook H. D., Cummings A.: The transmission loss of double panels. JSV, 1967. 6: p. 324-334.

[24] Cummings, A. and Mulholland, K. A.: The transmission loss of finite sized double panels in a random incidence sound field. JSV, 1968. 8: p. 126-133.

[25] Crocker M. J., Price, A. J.: Sound transmission using statistical energy analysis. JSV, 1969. 9: p. $469-486$.

[26] Price A. J., Crocker M. J.: Sound transmission through double panels using statistical energy analysis. JASA, 1970. 47(3): p. 683-693.

[27] Mulholland K. A., Price A. J., Parbrook H. D.: Transmission loss of multiple panels in a random incidence field. JASA, 1968. 43(6): p. 1432-1435.

[28] Hamada Y., Tachibana H.: Analysis of sound transmission loss of multiple structures by fourterminal network theory. Internoise 1985. Munich, Germany.

[29] Au A. C. K., Byrne K. P.: On the insertion losses produced by plane acoustic lagging structures. JASA, 1987. 82(4): p. 1325-1333.

[30] Au A. C. K., Byrne K. P.: On the insertion losses produced by acoustic lagging structures which incorporate flexurally orthotropic impervious barriers. Acustica 1990. 70: p. 284-291.

[31] Ver I. L.: Interaction of sound waves with solid structures, Noise and Vibration Control Engineering, 1992. John Wiley \& Sons Inc. New York, USA.

[32] Heckl M.: The tenth Sir Richard Fairey memorial lecture: Sound transmission in buildings. JSV, 1981. 77(2): p. 165-189. 
[33] Sharp B. H.: Prediction methods for the sound transmission of building elements. NCEJ, 1978. 11(2): p. 53-63.

[34] Cremer L., Heckl M.: Structure-borne sound, 1988. Springer-Verlag Berlin.

[35] Fahy F.: Sound and Strucutral Vibration. Radiation, Transmission and Response. 1985, The University Southampton, England: Academic press.

[36] Lin G.-F., Garrelick J. M.: Sound transmission through periodically framed parallel plates. JASA, 1977. 61(4): p. 1014-1018.

[37] Craik R. J. M., Wilson R.: Sound transmission through parallel plates coupled along a line. Appl Acoust, 1996. 49(4): p. 353-372.

[38] Sherry C.W., Green D.W.: Sound transmission loss off gypsum wallboard partitions - Report \#1. Unfilled steel stud partitions. JASA, 1982. 71(1): p. 90-96.

[39] Green D. W., Sherry, C.W.: Sound transmission loss off gypsum wallboard partitions - Report \#2. Steel stud partitions having cavities filled with glass fiber batts. JASA, 1982. 71(4): p. 902-907.

[40] Green D. W., Sherry C. W.: Sound transmission loss off gypsum wallboard partitions - Report \#3. 2x4 in. wood stud partitions. JASA, 1982. 71(4): p. 908-914.

[41] Oesterle E., Lieb R., Lutz M.: Doppelschalige Fassaden, Ganzheitliche Planung, 1999. Munchen: Callwey.

[42] Cheng W. F., Ng C. F., Fung K. C.: The theoretical model to optimize noise barrier performance at the window of a high-rise building. JSV, 2000. 238(1): p. 51-63.

[43] De Salis M. H. F., Oldham D. J., Sharples S.: Noise control strategies for naturally ventilated buildings. Build Environ, 2002. 37(5): p. 471-484.

[44] Lyons R., Gibbs B. M.: Investigation of an open screen acoustic performance. Appl Acoust, 1996. 49(3): p. 263-282.

[45] Oesterle L., Lutz H.: Double-skin Facades. 2001, Prestel Verlag, Berlin.

[46] EN 12354-1 Building Acoustics. Estimation of acoustic performance of buildings from the performance of elements. Part 1: Airborne sound insulation between rooms. 2001. 
[47] EN 12354-3 Building acoustics. Estimation of acoustic performance of buildings from the performance of elements. Part 3: Airborne sound insulation against outdoor sound. 2002.

[48] Blasco M., Crispin Ch.: Geventileerde Dubbele Gevels Akoestische Evaluatie In situ en labo metingen, modelisatie en evaluatie van de toepasbaarheid van de bestaande normalisatie. WTCB. 2004.

[49] Hopkins C., Lam Y.: Sound fields near building facades-comparison of finite and semiinfinite reflectors on a rigid ground plane. Appl Acoust, 2009. 70(2): p. 300-308.

[50] Gompeters M. C.: The sound insulation of circular and slit-shaped apertures. Acta Acust, 1964. 14(1): p.1-16.

[51] Wilson G. P., Soroka W. W.: Approximation to the Diffraction of Sound by a Circular Aperture in a Rigid Wall of Finite Thickness. JASA, 1964. 36(5): p.1023-1023.

[52] Oldham D. J., Zhao X.: Measurement of the sound transmission loss of circular and slitshaped apertures in rigid walls of finite thickness by intensimetry. JSV, 1993. 161(1): p.119135.

[53] Gibbs B. M., Balilah Y.: The measurement of sound transmission and directivity of holes by an impulse method. JSV, 1989. 133(1): p.151-162.

[54] Barclay M., Kang J., Sharples S.: Combining noise mapping and ventilation performance for non-domestic buildings in an urban area. Build Environ, 2012. 52: p. 68-76.

[55] Bibby Ch., Murray H.: Laboratory measurement of the acoustical and airflow performance of interior natural-ventilation openings and silencers. Appl Acoust, 2015. 82: p.15-22.

[56] Bajraktari E., Lechleitner J., Mahdavi A.: Estimating the sound insulation of double facades with openings for natural ventilation. Energy Procedia, 2015. 78: p.140-145.

[57] Bajraktari E., Lechleitner J., Mahdavi A.: The Sound Insulation of Double Facades with Openings for Natural Ventilation. Building Acoustics, 2014. 22 (3+4): p. 163-176.

[58] Huckemann V., Leão É.B., Leao M.: Acoustic comfort in office buildings with double skin glass façades. Bauphysik, 2009. 31(5): p. 305-312.

[59] Patrício J., Santos A., Matias L.: Double-skin Facades: Acoustic, Visual and Thermal Comfort Indoors. Proceedings of Healthy Buildings, 2006. p. 37-42. 
[60] Batungbakal A.: The acoustic performance of double-skin facades: A design support tool for architects. 2013.

[61] EN ISO 16283-1:2014 Acoustics - Field measurement of sound insulation in buildings and of building elements - Part 1: Airborne sound insulation. 2014.

[62] IEC 61672-1:2013 Electroacoustics - Sound level meters Part 1: Specifications.

[63] EN ISO 3382-2:2009 Acoustics.Measurement of room acoustic parameters. Part 2: Reverberation time in ordinary rooms.

[64] Urbán D., Zat’ko P., Dlhý D., Tomašovič P., Rychtáriková M., Glorieux C., Roozen N. B.: Standing waves in the cavity of double transparent facades. Forum Acusticum 2014. Krakow.

[65] Bielek B. et al.: Dvojité transparentné fasády budov 2 (Double transparent facades 2). 2002, Bratislava: COREAL.

[66] EN ISO 16283-3:2016 Acoustics - Field measurement of sound insulation in buildings and of building elements - Part 3: Façade sound insulation.

[67] ISO 10140-4:2010 Acoustics - Laboratory measurement of sound insulation of building elements. Part 4: Measurement procedures and requirements.

[68] ISO 10140-2:2010 Acoustics - Laboratory measurement of sound insulation of building elements., Part 2: Measurement of airborne sound insulation.

[69] ISO 10534-1:1996 Acoustics - Determination of sound absorption coefficient and impedance in impedances tubes, Part 1: Method using standing wave ratio.

[70] ISO 9053:1991 Acoustics. Materials for acoustical applications. Determination of airflow resistance.

[71] ISO 3382-2:2008 Acoustics. Measurement of room acoustic parameters, Part 2: Reverberation time in ordinary rooms.

[72] IEC 61260:1995 Electroacoustics. Octave-band and fractional-octave-band filters.

[73] IEC 60942:2003 Electroacoustics. Sound calibrators.

[74] Roozen N. B., Labelle L., Rychtarikova M., Glorieux, C.: Determining radiated sound power of building structures by means of Laser Doppler vibrometry. JASA, 2015. 346: p. 81-99. 
[75] Roozen N.B., Leclere Q., Glorieux C., Rychtarikova M.: A global error estimator for the uncertainty of a multi-channel spectral analysis. Appl Acoust, 2015. 87: p. 57-63.

[76] Dijckmans A., Vermeir G.: Numerical investigation of the repeatability and reproducibility of laboratory sound insulation measurements. Acta Acust, 2013. 99: p. 421-432.

[77] Osipov A., Mees P., Vermeir G.: Low-Frequency Airborne Sound Transmission through Single Partitions in Buildings. Appl Acoust, 1997. 52: p. 273-288.

[78] Wittstock V.,: On the Uncertainty of Single-Number Quantities for Rating Airborne Sound Insulation. Acta Acust, 2007. 93: p. 375 - 386.

[79] Machimbarrena M., Monteiro C. R. A., Pedersoli S., Johansson R., Smith S.: Uncertainty determination of in situ airborne sound insulation measurements. Appl Acoust, 2015. 98: p. 199-210.

[80] Mahn J., Pearse J.: The Uncertainty of the Proposed Single Number Ratings for Airborne Sound Insulation. Building Acoustics, 2012. 19: p. 145-172.

[81] Gibbs B.M., Maluski S.: Airborne Sound Level Difference Between Dwellings at Low Frequencies. Building Acoustics, 2004. 11(1): p. 61-78.

[82] Nielsen T.G., Jacobsen F.: Spatial correlation and coherence in a reverberant sound field, JSV, 1987. 118: p. 175-180.

[83] ISO 10140-2:2010 Acoustics. Laboratory measurement of sound insulation of building elements. Part 2: Measurement of airborne sound insulation.

[84] Stepanishen P. R., Fisher G.: Experimental verification of the impulse response method to evaluate transient acoustic fields. JASA, 1981. 69: p.1610-1617.

[85] Dietrich P. et. al: ITA-Toolbox- An Open Source MatLab Toolbox for Acousticians, DAGA. 2012.

[86] Rife D. D., Vanderkooy J.: Transfer-function measurement with maximum-length sequences. JAES, 1989. 37: p. 6.

[87] ISO 18233 Acoustics. Application of new measurement methods in building and room acoustics. 2006.

[88] Sabine, W. C.: Collected Papers on Acoustics Peninsula, Los Altos, CA. 1900-1915. 
[89] Schroede.Mr: New Method of Measuring Reverberation Time. JASA, 1965. 37(6): p. 1187-\&.

[90] Schroeder, M. R.: Frequency-Correlation Functions of Frequency Responses in Rooms. Journal of the Acoustical Society of America, 1962. 34(12): p. 1819-\&.

[91] Bies, D. L. : "Noise and Vibration Control " (L. L. Beranek, ed.), 1971.

[92] London, A.: Transmission of Reverberant Sound through Double Walls. JASA, 1950. 22.

[93] J., Čechura: Stavební fyzika 10-akustika stavebních konstrukcí. 1997, Praha: ČVUT.

[94] Brekke, A.: Sound transmission through single and double-leaf partitions (Norwegian). 1979, Inst. for Husbyggingsteknikk,NTH.: Trondheim, Norway.

[95] Rindel, J. H.: Transmission of traffic noise trough windows. Lyngby. 1975, Technical University of Denmark. 